amphetamine and tranylcypromine, inhibit monoamine oxidase, though more powerfully. Several trials ${ }^{5-14}$ have shown that they are more often effective than dummies, but the differences are slight and suggest that only about one patient in ten benefits even for a short time from their use. There is no clear evidence that the effectiveness of these drugs actually depends on their capacity to inhibit amine oxidase, although attractive theories about their mode of action can be constructed to rationalize their use.

The hydrazines are liable to cause serious ill-effects in a small proportion of patients, including jaundice, which is sometimes fatal, ${ }^{15} 16$ agranulocytosis, and hypotension ; one member of this group ("cavodil") has been withdrawn from the market, as has another non-hydrazine amine oxidase inhibitor, "monase." Potentiation of morphine, pethidine, and other analgesics, and also of barbiturates and alcohol, has been reported, with severe and sometimes fatal consequences. ${ }^{17}$ In view of the widespread use of these central depressant drugs and the impracticability of protecting patients from any exposure to them, it is evident that the use of these drugs carries an appreciable risk as well as limited benefit.

\section{Iminodibenzyl Derivatives}

The most effective drugs in relieving depression appear to be imipramine ("tofranil ") $11{ }^{13} 18-20$ and its close relation amitriptyline ("laroxyl," "saroten," "tryptizol "). ${ }^{2122}$ They do not inhibit amine oxidase, but have some chemical similarity to chlorpromazine which is not sufficient to suggest that they are necessarily acting on the same nerve cells. Numerous trials show that they are more effective than any of the amine oxidase inhibitors, but less effective in severe depression than electroconvulsive therapy. Combined with E.C.T. they substantially reduce the relapse rate. ${ }^{19}$ No individual symptoms in depressed patients appear to be particularly related to a successful response to imipramine, ${ }^{23}$ though the older patients with short histories and an absence of neurotic features on the whole respond better. ${ }^{24}$

They are moderately toxic, causing especially dryness of the mouth, other symptoms and signs of parasympathetic blockade, and drowsiness. All these effects diminish with repeated administration. More drastic toxic effects are not generally recognized, but neither drug has been in use for so long that it can be assumed to be innocuous.

\section{General Considerations}

None of these drugs appears to have been tested extensively for possible injurious effects to foetuses, and it is probably inexpedient to use them in women who are or may be pregnant without proper regard for a risk of uncertain magnitude Likewise there appear to be no observations on their excretion in milk, nor on the effects on infants of such quantities of drug as may reach them in this way. Puerperal depression is on the whole a self-limiting condition, and the use of antidepressive drugs for its amelioration is justifiable only if the disease is severe enough to warrant the uncertain but inevitable risks, and if a proper evaluation of any attempted therapy is carried out in the course of treatment.

The overall treatment of the depressed patient is not greatly advanced by drugs. For a small number of patients imipramine or amitriptyline may provide an alleviation which avoids electroconvulsive therapy, and for rather more patients receiving E.C.T. these drugs are likely to reduce the rate of relapse. The milder depressions are often self-limiting, and the various illeffects of the amine oxidase inhibitors are a salutary warning against taking precipitate or unconsidered refuge in the administration of drugs which are sometimes more powerful than useful.

\section{REFERENCES}

1 Peoples, S. A., and Guttmann, E., Lancet, 1936, 1, 1107. 3 Kiloh, L. G., and Brandon, S., Brit. med. J.. 1962, $2,40$. 3 Hare, E. H., Dominian, J., and Sharpe, L., ibid., 1962, 1, 9. - Legge. D., and Steinberg,"H., Brit. J. Pharmacol., 1962, 18 440

' Overall, J. E., Hollister, L. E., Pokorny, A. D., Casey, J. F., and Katz. G., Clin. Pharmacol. Ther., 1962, 3, 16.

- Bartholomew, A. A., Med. J. A ust.. 1962, 1. 655.

Freyhan, F. A., Amer. J. Psychiat., 1960, 116. 1057

Affleck, J. W., Forrest, A. D., and Martin, F. M., J. ment. Sci., 1961 107, 997.

- Bates, T. J., and Douglas, A. D., ibid., 1961, 107, 538.

10 Crisp, A. H., Hays, P., and Carter, A.. Lancet. 1961, 1, 17

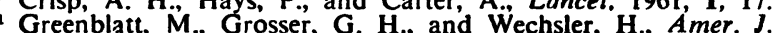
Psychiat. 1962, $119,144$.

12 Lear, T. E., Browne, M. W., and Greeves, J. A., J. ment. Sci., $1962,108,856$

${ }^{13}$ Rothman, T., Grayson, H., and Ferguson, J., J. Neuropsychiat. 1962. 3, 234.

"Stanley, W. J., and Fleming. H., J. ment. Sci., 1962, 108, 708

15 Holdsworth, C. D., Atkınson, M., and Goldie, W., Lancet, $1961,2,621$.

16 Jolly. E. R., Circularion. 1959, 20.1.

17 Taylor, D. C., Lancet, 1962, 2, 401

18 Kiloh, L. G., and Ball, J. R. B., Brit. med. J., 1961, 1, 168.

19 Seager, C. ., and Ball, J. R. B., Brit. med. J., 1961, $1,168$.

${ }^{20}$ Weager, C. P., and Bird. R. L., J. ment. Sci., 1962, 108. 704 . J. nerv. ment. Dis., 1962,135, 131 .

${ }^{3}$ Burt, C. G., Gordon, W. F. Holt, N. F., and Hordern, A. J. ment. Sci., 1962, 108, 711

${ }^{22}$ Skarbek, A.. and Smedberg, D., ibid., 1962, 108. 859.

${ }^{23}$ Fleminger, J. J., and Groden, B. M., ibid., 1962, 108, 101.

Kiloh, L. G. Ball, J. R. B., and Garside, R. F., Brit. med. J. $1962,1,1225$.

Correction.-In “To-day's Drugs" (January 12, p. 107) it was stated that the hypnotic carbromal could be bought freely without a prescription. This was incorrect. Carbromal is now subject to the provisions of Schedule $4 \mathrm{~B}$ of the Poisons Rules 1960 and may be supplied to the public only on a prescription.

\section{APPROVED NAMES}

The last supplement to the consolidated list of "approved names" was published in the Journal of November 10, 1962 (p. 1253). A new supplement, dated December, 1962, is printed below. Communications relating to "approved names" should be addressed to the Secretary, British Pharmacopoeia Commission, General Medical Council, 44 Hallam Street, London W.1.

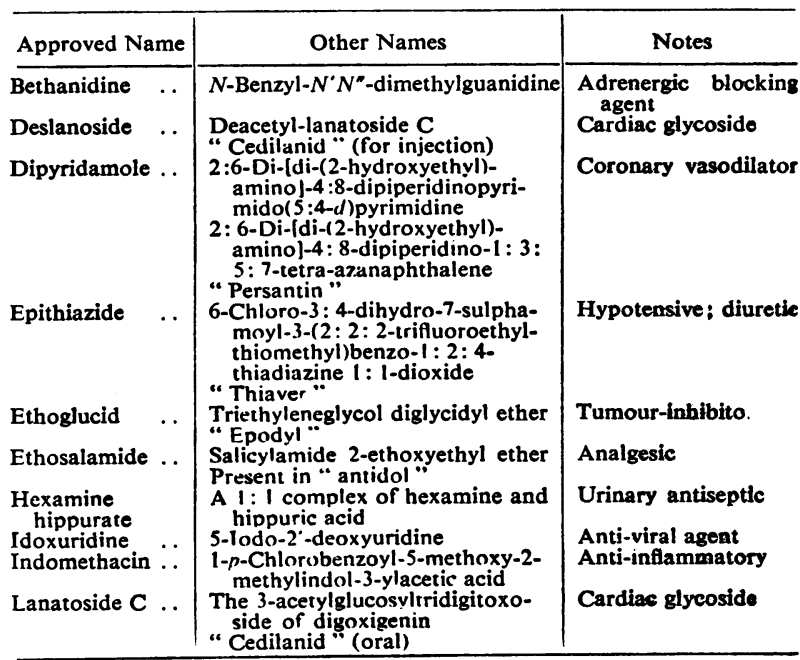

(Continued on mext pege) 